\title{
Learning Effectiveness and Efficiency in Tertiary Mathematics Education under Core-and-Spoke Model
}

\author{
Chia-Ying Khor, Fang-Fang Chua, and Tek-Yong Lim
}

\begin{abstract}
In Malaysia, traditional teaching approach is still the most common approach used in the tertiary mathematics education. Under the traditional teaching approach, students learn mathematics through rote-learning and being "spoon-fed". Traditional teaching approach may lead to students have loss of interest in learning mathematics and consequently, students seriously do not reach in-depth understanding of mathematics. This shows that students do not learn mathematics effectively and efficiently. The motivation of this research is to find out student's learning effectiveness and efficiency in learning the tertiary mathematics course under a designed blended learning approach that incorporates the core-and-spoke model. A preliminary statistical analysis is conducted at early stage to give a better understanding on the collected data. The analysis of student's learning effectiveness is carried out based on the student's learning outcome achievement and learning satisfaction. Technical efficiency in data envelopment analysis (DEA) is employed to evaluate the student's learning efficiency. The results show that the students not only have more interest in learning the tertiary mathematics, but also they are able to learn in a more effective and efficient way under the designed blended learning approach.
\end{abstract}

Index Terms-Blended learning, learning effectiveness, learning efficiency, tertiary mathematics.

\section{INTRODUCTION}

Tertiary mathematics education is a critically essential education and becomes core to most of courses offered by higher education institutions (HEI). According to Malaysia Education Blueprint (2015-2025) (Higher Education) or MEB (HE) [1], the ministry emphasized on thinking skill and knowledge, which are 2 out 6 primary attributes that each individual student should exhibit. Under MEB (HE), one of the focuses (Shift No. 9) is on globalized online learning. The swift growth in technological innovation has advocated the adoption of blended learning approaches in teaching and learning in HEIs. Blended learning approach is broadly defined as the combination of the strengths of face-to-face (F2F) learning mode and online learning mode [2]. Therefore, with the current advanced technology and alignment with MEB (HE), HEIs in Malaysia are facing learning tools transformation.

In Malaysia, traditional teaching approach is still the most common approach used in the tertiary mathematics education. There is a belief that mathematics is different from other disciplines where there is no require to move away from

Manuscript received February 2, 2020; revised May 18, 2020.

Chia-Ying Khor, Fang-Fang Chua, and Tek-Yong Lim are with the Faculty of Computing and Informatics, Multimedia University, Malaysia (e-mail: $\quad$ cykhor@mmu.edu.my, $\quad$ ffchua@mmu.edu.my, tylim@mmu.edu.my). classroom physically. Lecturing mathematics in classroom has appeared naturally to many mathematics lecturers who themselves were taught in the same way of traditional approach. Under the traditional teaching approach, students learn mathematics through rote-learning and being "spoon-fed", which may obstruct the enthusiasm to learn and creativity of students. Apparently, students could only apply fundamental mathematics knowledge in straightforward and simple problems. This indicates that the students do not reach in-depth understanding of mathematics. Billman, Harding and Engelbrecht conducted a case study on the integration of technology into teaching at mathematics department [3]. The study showed that chalkboards are still more suitable than technology for teaching mathematics. But, they also claimed that the use of technology has become a necessity in teaching large groups. The transition from traditional way of teaching to blended learning way using technology is a remarkable trend for them to move forward.

The evolution of teaching approaches with the utilization of blended learning models has drawn researchers' attention. Literally speaking, there is still a limited research studies carried out on blended learning, specifically in the tertiary mathematics education. Based on the aforementioned problems appeared in learning tertiary mathematics using the traditional teaching approach, the hypothesis of our study is as below:

1. Students are more interested in learning the tertiary mathematics course under blended learning approach.

The rest of this paper is structured as follows. Literature review on blended learning models, the implementation of blended learning models in learning, its learning effectiveness and learning efficiency are described in the next section. Followed by the explanation of methodology used in the designed blended learning approach in learning a selected tertiary mathematic course. Some preliminary statistical results and discussion on learning effectiveness and efficiency are presented at Section 4. Conclusion is made at the last section.

\section{LITERATURE REVIEW}

\section{A. Blended Learning Models}

By adopting the blended learning approach, the learning process is more dynamic and interactive. Using blended learning models, students' learning eagerness may be enhanced and subsequently, students are motivated and keen in learning tertiary mathematics. There are many blended learning models nowadays which are significantly proven as the improvements in education and technology. 
Four common blended learning models that are widely used in education, namely rotation model, flex model, a la carte model and enriched virtual model. The rotation model requires learners to appear physically on campus and contains four sub-models, namely station rotation, lab rotation, flipped classroom and individual rotation. The flex model allows the learners to switch between learning modalities on a more flexible and customized schedule. The a la carte model is a model that the learners can learn one or more than one courses online. In the enriched virtual model, the learning process is divided into online and offline components. Students do not need to appear physically on campus every day. There are also other models such as skill-driven model, attitude-driven model and competency-driven model, used specifically in adult training courses. In recent years, program-flow model, core-and-spoke model and network model are used in education as well. The main difference between core-and-spoke model and network model is that there is no core shared experiences in network model.

In our study, core-and-spoke model is adopted in the designed blended learning approach. The main reason is that it is a necessary for students to learn a primary mathematics topic together and subsequently allowing students to further explore that topic in deep either individually or in small groups. Fig. 1 shows the core-and-spoke model. From the primary topic ("1" in Fig. 1), several relevant materials ("a" to "e" in Fig. 1) are branched out for students to expand and deepen their own knowledge on that primary mathematics topic at their own pace.

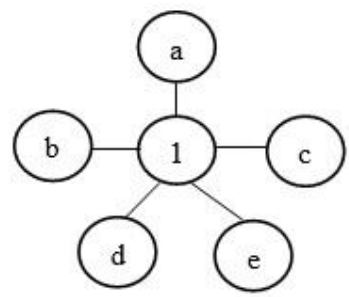

Fig. 1. Core-and-spoke model.

\section{B. Implementation of Blended Learning Models; its Effectiveness and Efficiency}

Some researchers have shown the effectiveness and efficiency of implementation of blended learning in education. Indicators such as learning achievement, attitude and the end of result of teaching are used to evaluate the learning effectiveness. The learning efficiency can be measured by the flexibility of using different methods and tools in the learning environment, the number of correctness in a given assignment divided by time in minutes and others.

There are few studies about students' performance and perceptions on using blended learning approaches in their course. Majority students are found to have more favor in learning under blended learning environment (BLE) and also there is a notable improvement in their examination marks. Researchers recommended that students could have given opportunity to choose to learn through different approaches, especially low achievers that faced challenging in coping with blended learning approach. Also, the findings in [4], [5] and [6] showed that students' learning desire, learning process, learning method, mathematics beliefs are positive and statistically significant. The outcomes of survey that were conducted on students' attitudes, perceptions and engagement during the implementation of flipped classroom blended learning model in mathematics education revealed that students' perceptions and attitudes are positive.

The influences and effect of blended teaching in mathematics learning were investigated for junior high schools too. Overall, the results in [5] and [7] showed that the students are more motivated in learning mathematics under BLE. Ardana, Ariawan and Divayana [8] conducted experiment on the implementation of different blended learning tools at a secondary school. The result showed that among selected blended learning approaches, students and teachers have the best learning and teaching experience in mathematics subject via Edmodo blended learning tool. Howard, Meehan and Parnell [9] integrated live lectures or online videos into their first-year university mathematics module. They analyzed the impact of the integration using thematic analysis and found out on average, students have high attendance rate and higher marks. A study on the blending a massive open online courses (MOOC) in a traditionally taught course was carried out and qualitative approach was used to analyze students' learning diaries [10]. Their findings showed that the students have positive motivation if they are given choices to choose courses that they are most interested in MOOC.

Since there are numerous positive feedbacks on the success of implementing blended learning models into education, there is a need to adopt blended learning approach in the tertiary mathematics education in Malaysia's HEIs.

\section{Methodology}

\section{A. Structure of the Designed Blended Learning Approach}

In this study, a blended learning approach using core-and-spoke model is designed for tertiary mathematics course. The chosen tertiary mathematics course is Computational Methods that is offered by Faculty of Computing and Informatics (FCI), Multimedia University. The selected course is conducted for 14 weeks and the assessment is done until week 16. The topics in Computational Methods course include locating roots of equations, numerical integrations, Monte Carlo, systems of linear equations, least square problems, interpolation and polynomial approximation.

There are 79 students enrolled in Computational Methods who are selected as test sample. Majority of the enrolled students are first year students. The designed blended learning approach comprises two components, face-to-face (F2F) learning and online learning. Overall, students have 3 weeks of online learning and 11 weeks of F2F learning. Quiz assessment is conducted at the end of the week of F2F or online learning to test student's understanding level on a given learnt topic. One midterm test is conducted in week 11. Assignment is distributed in week 6 and required to submit by week 14 . Students have to sit for final examination that is 
held in week 16. Fig. 2 shows the design of blended learning approach used in the selected course.

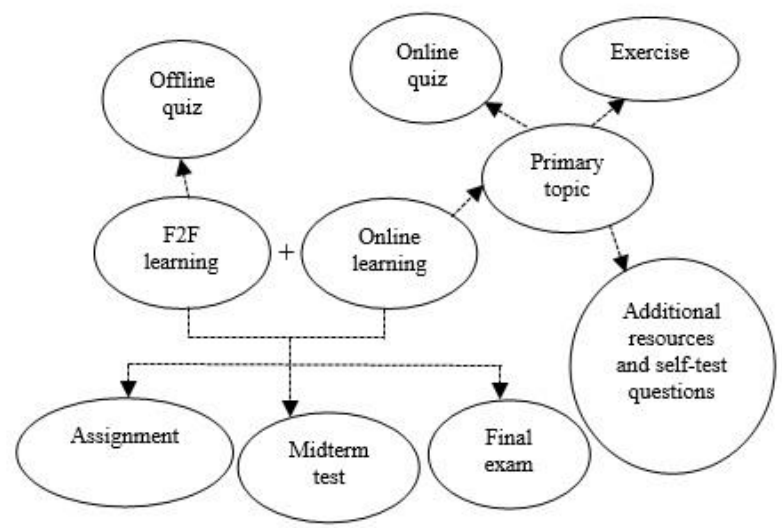

Fig. 2. Design of the blended learning approach with incorporating the core-and-spoke model in the online learning component.

In the F2F learning component (see Fig. 2), the lecturer firstly explains the overview of the course and ensures that the students are clear with the course learning outcomes. Students are taught physically in classroom and do tutorials either in lab or tutorial room.

In the online learning component that uses core-and-spoke model (see Fig. 2), the lecturer gives students a brief idea and quick understanding on a primary topic. Instead of learning in a big group like in $\mathrm{F} 2 \mathrm{~F}$ component, the students are formed randomly into few small learning groups. The intention of having small learning groups is to provide a focus discussion platform within the group members as well as allowing lecturer to have closer monitoring on student's study performance. Google Classroom is used as the online learning platform.

Under the primary topic, each small learning group is provided with different extra materials such as helpful resources and exercises. The students are required to learn the topic comprehensively at their own pace during a certain time frame. During the given time frame, the lecturer and students can have discussion using a provided platform. To assess student's understanding level on that primary topic, students are required to complete online quiz. Each learning group has different online quiz. They have to submit the online quiz within given time frame. Fig. 3 displays the timeline for the designed blended learning approach in duration of weeks.

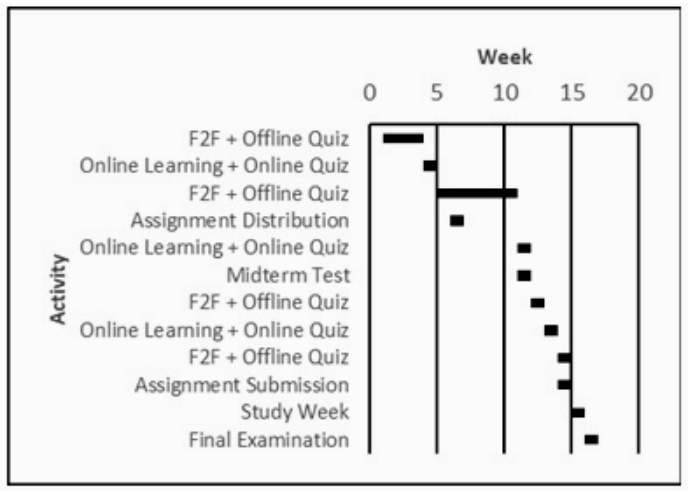

Fig. 3. Design of the blended learning approach with incorporating the core-and-spoke model in the online learning component.
In Fig. 3, the students have 3 weeks of online learning and 11 weeks of F2F learning. The quiz assessment is conducted at the end of week of F2F or online learning to test the student's understanding level on the learnt topic. One midterm test is conducted in week 11. Assignment is distributed in week 6 and required to submit by week 14 . The students have to sit for final examination that is held in week 16.

To understand student's study performance in tertiary mathematics course under the designed blended learning approach, analyses are conducted from the perspectives of learning effectiveness and learning efficiency. The methodologies used to measure the student's learning effectiveness and learning efficiency are described in Sections III(b) and III(c).

\section{B. Learning Effectiveness Methodology}

A survey is carried out to evaluate the student's learning effectiveness. Three aspects of student's learning perceptions on learning mathematics course under the blended learning approach namely course learning outcomes achievement, student's satisfaction on the blended learning approach and learning interactive between students and lecturer are concerned. The Cronbach's alpha coefficient is computed to ensure the reliability of the designed survey. The Cronbach's alpha with a coefficient at least 0.7 indicates that the survey is highly reliable. Preliminary statistics and inter-item correlation analyses are then conducted using SPSS. This is to deepen our understanding on student's learning effectiveness.

\section{Learning Efficiency Methodology}

To evaluate the student's learning efficiency under the designed blended learning approach, a student's study achievement throughout his/her study progress is observed and analyzed. Technical efficiency (TE) in Data Envelopment Analysis (DEA) is employed to evaluate the learning efficiency [11]. The main reason of selecting DEA in learning efficiency evaluation is that the DEA is able to handle multiple inputs and outputs which yields the efficiency measurement. In our study, TEs for the designed blended learning approach, fully F2F approach and fully online approach are measured and compared. This leads us to have three decision making units (DMU). The equation of TE is displayed in (1).

$$
\text { Technical Efficiency, } T E_{k}=\sum_{j}^{M} v_{j} y_{j k} / \sum_{i}^{N} u_{i} x_{i k}
$$

where

$k-$ DMU that $T E$ is being measured $(1,2,3)$

$M$ - Number of outputs $(j=1,2, \ldots, M)$

$N$ - Number of inputs $(i=1,2, \ldots, N)$

$v_{j}$ - Weight of outputs $\left(j=1,2,{ }_{+} M\right)$

$u_{i}$-Weight of inputs $(i=1,2, \ldots, N)$

$y_{j k}$ - Observed level of of outputs $(j=1,2, \ldots, M)$

$x_{i k}$ - Observed level of of inputs $(i=1,2, \ldots, N)$

For each TE, we maximize (1) and subject to $\sum_{j}^{M} v_{j} y_{j k} / \sum_{i}^{N} u_{i} x_{i k} \leq 1$ for $k=1,2$, 3. A high technical 
efficiency value which is close to 1 indicates that students are able to learn tertiary mathematics efficiently under the designed blended learning approach.

\section{RESULTS AND DISCUSSION}

The student's study performance in Computational Methods course under the designed blended learning approach is analyzed based on two perspectives, learning effectiveness and learning efficiency. The findings are described in Sections IV(a) and IV(b).

\section{A. Learning Effectiveness}

A survey was conducted to evaluate the student's learning effectiveness. The survey comprises two parts. Part A is about student's understanding level on the implemented blended learning approach. Part B is designed using 5-point Likert Scale. The questions mainly focus on learning outcomes achievement, student's satisfaction level on the designed blended learning approach and learning interaction between students and lecturer. The computed Cronbach's alpha coefficient is 0.858 that indicates the survey is highly reliable. There is $65 \%$ of students who took the course participated in the survey and $80 \%$ of them are male.

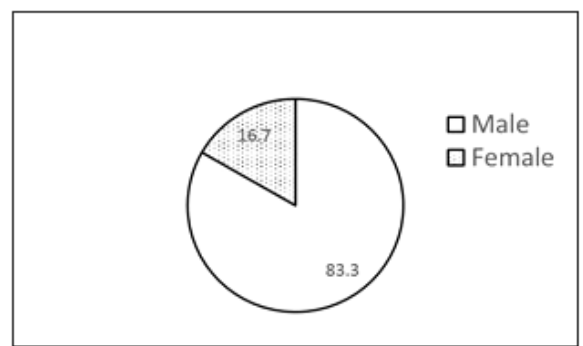

Fig. 4. Pie chart of the gender of respondents in percentage.

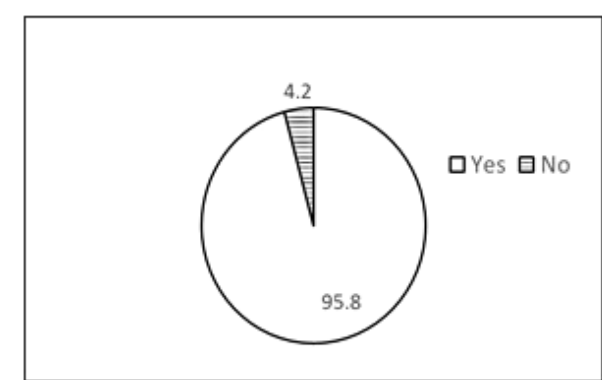

Fig. 5. Pie chart of the respondent's first time enrollment in Computational Methods course in percentage.

Fig. 4 and Fig. 5 display that there is $83.3 \%$ of respondents are male and there is only a minor group of respondents who took the course more than one time respectively.

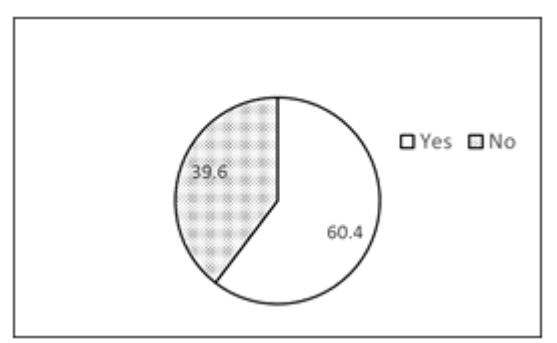

Fig. 6. Pie chart of the respondent's first time experience of using blended learning approach in learning mathematics in percentage.

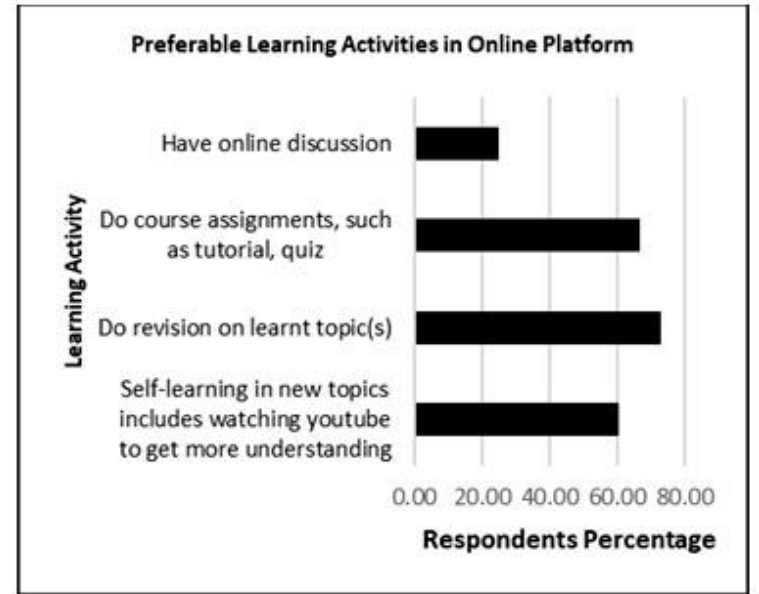

Fig. 7. Bar graph of the respondent's preferable learning activities in online platform when learning mathematics.

Fig. 6 tells us that there is around $60 \%$ of students have their first time experience in learning mathematics course using blended learning approach. In Fig. 7, under the implementation of the designed blended learning approach, most of the respondents would like to prefer to have revision on learnt mathematics topic(s) on online platform, followed by doing course assignment and self-learning in new topics which includes watching YouTube as well. There is only around $25 \%$ of respondents who prefer to have online discussion either with peers or instructor.

11 survey statements in part B of survey are categorized according to the three aspects of student's learning perceptions (refer to Section III(b)). Table I shows the average responses in percentage on the categorized student's learning perceptions.

TABLE I: CATEGORIZED SURVEY STATEMENTS AND AVERAGE RESPONSES

\begin{tabular}{|c|c|c|c|c|c|}
\hline \multicolumn{6}{|c|}{ IN PERCENTAGE } \\
\hline Category & $\begin{array}{l}\text { SA } \\
(\%)\end{array}$ & $\begin{array}{l}\text { A } \\
(\%)\end{array}$ & $\begin{array}{l}\mathrm{N} \\
(\%)\end{array}$ & $\begin{array}{l}\text { D } \\
(\%)\end{array}$ & $\begin{array}{l}\text { SD } \\
(\%)\end{array}$ \\
\hline $\begin{array}{l}\text { Learning Outcome } \\
\text { Achievement }\end{array}$ & 22 & 33.5 & 41.5 & 3 & 0 \\
\hline $\begin{array}{l}\text { Satisfaction Level on the } \\
\text { designed Blended Learning } \\
\text { Approach }\end{array}$ & 20.7 & 37.2 & 33.8 & 8 & 0.3 \\
\hline $\begin{array}{l}\text { Learning Interaction } \\
\text { between students and } \\
\text { instructor }\end{array}$ & 13 & 34.5 & 35.5 & 13.5 & 3.5 \\
\hline
\end{tabular}

In Table I, majority respondents show positive responses in learning Computational Methods under the designed blended learning approach. Most of the students have neutral response on the coursework assessment completion that reflects their learning outcome achievement. For the satisfaction level on the designed blended learning approach, students are pretty satisfied with the blended learning approach, on average. However, an interesting fact is found in the learning interaction between students and instructor. Majority of students prefer to have F2F interaction with instructor rather than online interaction even though they prefer to learn mathematics under the designed blended learning approach. They feel it is easier to gain better understanding when discussion is carried out through F2F mode. 


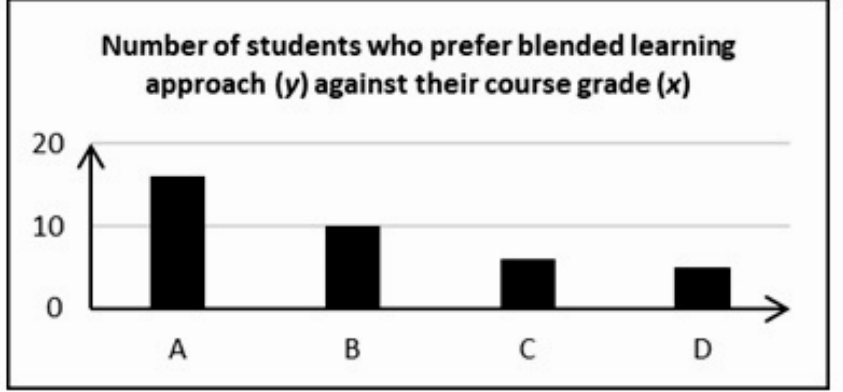

Fig. 8. Bar graph of the number of students who prefer blended learning approach $(y)$ against their course grade $(x)$.

Fig. 8 shows the students' course grade who are satisfied with learning Computational Methods under the designed blended learning approach. 16 students scored A in Computational Methods which is the highest number of students across course grades. This reveals that students could score better when they learn under the designed blended learning approach.

Inter-item correlation matrix is computed to check the strength of relationship among the statements in the survey. Table II gives the highest three correlation value among all the 11 survey statements.

TABLE II: THE THREE HIGHEST INTER-ITEM CORRELATION

\begin{tabular}{|c|c|c|}
\hline No. & Survey Statement & $\begin{array}{c}\text { Inter-item } \\
\text { Correlation }\end{array}$ \\
\hline 1. & $\begin{array}{l}\text { (g) I am more engaged with mathematics } \\
\text { course when it is in blended learning } \\
\text { mode. } \\
\text { (i) I would prefer to learn mathematics in } \\
\text { blended learning mode if given the } \\
\text { opportunity. }\end{array}$ & 0.831 \\
\hline 2. & $\begin{array}{l}\text { (a) I spend lesser time to complete course } \\
\text { assignments online as compared to } \\
\text { traditional way. } \\
\text { (b) I am able to submit online course } \\
\text { assignments in given time } \\
\text { frame as compared to traditional way. }\end{array}$ & 0.749 \\
\hline 3. & $\begin{array}{l}\text { (a) I spend lesser time to complete course } \\
\text { assignments online as compared to } \\
\text { traditional way. } \\
\text { (e) I am more comfortable to learn } \\
\text { mathematics at my own pace in } \\
\text { blended learning mode. }\end{array}$ & 0.700 \\
\hline
\end{tabular}

According to Table II, statements (g) and (i) have the strongest positive relationship. It indicates that students who prefer blended learning approach feel that they are more engaged in learning mathematics course. The relationship between the statements (a) and (b) is a pretty strong positive relationship. It shows that the students who are able to submit online course assignments on time also can manage to complete their online course assignments at much earlier time. Statements (a) and (e) have a pretty strong positive relationship as well which reveals that students who prefer to have own learning pace in blended learning approach are able to submit their online course assignments on timely manner.

\section{B. Learning Efficiency}

As mentioned in Section III(c), three technical efficiencies (TE) are measured and compared. Across the three TEs, five inputs and five outputs are considered under either the designed blended learning (BL) approach, fully face-to-face
(F2F) approach or fully online $(\mathrm{O})$ approach. The inputs $\left(x_{i k}\right)$ and outputs $\left(y_{j k}\right)$ that are concerned stated below:

For approach, $k=1(\mathrm{BL}), 2$ (F2F), $3(\mathrm{O})$ :

Five inputs:

$x_{1 k}$ - Number of students who prefer to have study materials under $k^{\text {th }}$ learning approach

$x_{2 k}-$ Number of students who prefer to study under $k^{\text {th }}$ learning approach

$x_{3 k}$ - Number of students who prefer to have learning activities under $k^{\text {th }}$ learning approach

$x_{4 k}$ - Number of students who prefer to have self-learning under $k^{\text {th }}$ learning approach

$x_{5 k}$ - Number of students who agree that the speed of learning increases under $\mathrm{k}^{\text {th }}$ learning approach

Five outputs:

$y_{1 k}-$ Number of students who score A in midterm test under $k^{\text {th }}$ learning approach

$y_{2 k}-$ Number of students who score $\mathrm{A}$ in offline quiz under $k^{\text {th }}$ learning approach

$y_{3 k}-$ Number of students who score $\mathrm{A}$ in assignment under $k$ learning approach

$y_{4 k}-$ Number of students who score A in online quiz under $k^{\text {th }}$ learning approach

$y_{5 k}-$ Number of students who score A in final exam under $k^{\text {th }}$ learning approach

In our study, Microsoft Excel Solver Linear Programming tool is used to optimize, solve and compute the three technical efficiencies. The objective functions are to maximize $T E_{k}, k=1,2,3$ and subject to the following constraints:

$$
\begin{gathered}
0.1640 y_{1 k}+0.1812 y_{2 k}+0.0085 y_{3 k}+0.0384 y_{4 k}+0.0039 y_{5 k} \\
\leq 0.0013 x_{1 k}+0.0295 x_{2 k}+0.0180 x_{3 k}+0.0108 x_{4 k}+0.0127 x_{5 k} \\
x_{1 k}, x_{2 k}, x_{3 k}, x_{4 k}, x_{5 k}, y_{1 k}, y_{2 k}, y_{3 k}, y_{4 k}, y_{5 k} \geq 0
\end{gathered}
$$

The computed technical efficiencies are tabulated in Table III.

TABLE III: TECHNICAL EFFICIENCY FOR THE THREE APPROACHES:

\begin{tabular}{|l|l|}
\hline \multicolumn{1}{|c|}{ BLENDED LEARNING, FULLY F2F AND FULLY ONLINE } \\
\hline \multicolumn{1}{|c|}{$k$} & $T E_{k}$ \\
\hline 1 (BL Approach) & 1 \\
\hline 2 (Fully F2F Approach) & 0.86 \\
\hline 3 (Fully Online Approach) & 0.72 \\
\hline
\end{tabular}

Refer to Table III, the technical efficiency for students who prefer to study Computational Methods under the implemented blended learning approach $\left(T E_{1}\right)$ has a value of 1 that is the highest among those three. It shows that students are able to learn the tertiary mathematics more efficiently under the realized blended learning approach. It also indicates that the failure rate in tertiary mathematics courses may decrease significantly if students learn under the designed blended learning approach. 


\section{CONCLUSION}

With the incorporation of core-and-spoke model in the implemented blended learning approach, it is found that the students are able to learn tertiary mathematics in a more effective and efficient way. As compared to the traditional approach of teaching and learning mathematics, the students show more initiative in exploring the mathematics topics that indirectly increases students' learning interest through the designed blended learning approach. It is very common that the failure rate in the tertiary mathematics education in Malaysia is pretty high. By increasing the students' enthusiasm in learning tertiary mathematics, it may lead to the decrement of failure rate in tertiary mathematics education in Malaysia. In future, the online discussion platform would be enhanced since majority of students show positive feedback in learning tertiary mathematics course using blended learning approach. Additionally, a study on collaborative learning in tertiary mathematics education under different blended learning approaches may be carried out.

\section{CONFLICT OF INTEREST}

The authors declare no conflict of interest.

\section{AUTHOR CONTRIBUTIONS}

All authors had approved the final version.

\section{ACKNOWLEDGMENT}

This work was supported by Multimedia University Mini Fund [MMUI/180151].

\section{REFERENCES}

[1] Malaysia Education Blueprint 2015-2025 (Higher Education).

[2] R. Boelens, S. Laer, B. Wever, and J. Elen. (2015). Blended learning in adult education: Towards a definition of blended learning. [Online]. Available:

http://www.iwt-alo.be/wp-content/uploads/2015/08/01-Project-reportBlended-learning-in-adult-education-towards-a-definition-of-blendedlearning.pdf

[3] A. Billman, A. Harding, and J. Engelbrecht, "Does the chalkboard still hold its own against modern technology in teaching mathematics? A case study," International Journal of Mathematical Education in Science and Technology, vol. 49, no. 6, pp. 809-823, 2018.

[4] K. R. Clark, "The effects of the flipped model of instruction on student engagement and performance in the secondary mathematics classroom," Journal of Educators Online, vol. 12, no. 1, pp. 91-115, 2015.

[5] C. Moore and C. J. Chung, "Students' attitudes, perceptions, and engagement within a flipped classroom model as related to learning mathematics," Journal of Studies in Education, vol. 5, no. 3, pp. 286-308, 2015.

[6] B. Loch and R. Borland, "The transition from traditional face-to-face teaching to blendend learning - implications and challenges from a mathematics discipline perspective," in Rhetoric and Reality: Critical
Perspectives on Educational Technology, B. Hegarty, J. McDonald, and S.-K. Loke, Eds. 2014, pp. 708-712.

[7] Y. W. Lin, C. L. Tseng and P. J. Chiang, "The effect of blended learning in mathematics course," EURASIA Journal of Mathematics, Sciences and \& Technology Education, vol. 13, no. 3, pp. 741-770, 2017.

[8] M. Ardana, P. W. Ariawan, and D. G. H. Divayana, "Development of decision support system to selection of the blended learning platforms for mathematics and ICT learning at SMK TI Udayana," International Journal of Advanced Research in Artificial Intelligence, vol. 5, no. 12, pp. 15-18, 2016.

[9] E. Howard, M. Meehan, and A. Parnell, "Live lectures or online videos: Students' resource choices in a first-year university mathematics module," International Journal of Mathematical Education in Science and Technology, vol. 49, no. 4, pp. 530-553, 2017.

[10] A. Bralic and B. Divjak, "Integrating MOOCs in traditionally taught course: Achieving learning outcomes with blended learning," International Journal of Educational Technology in Higher Education, vol. 15, no. 2, pp. 1-16, 2018.

[11] D. Halkiotis, I. Konteles, and V. Brinia, "The technical efficiency of high schools: The case of a Greek prefecture," Education Sciences, vol. 8 , no. 84, 2018.

Copyright $\odot 2020$ by the authors. This is an open access article distributed under the Creative Commons Attribution License which permits unrestricted use, distribution, and reproduction in any medium, provided the original work is properly cited (CC BY 4.0).

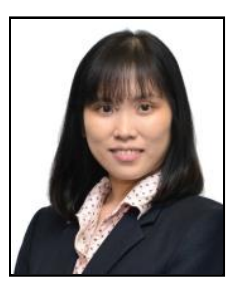

Chia-Ying Khor is a senior lecturer of the Faculty of Computing and Informatics, Multimedia University. She earned her bachelor of computer science (hons.) from University of Tunku Abdul Rahman (UTAR). She then obtained her master in statistics and $\mathrm{Ph}$. D (statistics) from University of Malaya. Her research interests include data analytics, prediction interval forecasting and stochastic process. She is involved in research projects funded by FRGS, mini fund and TM $\mathrm{R} \& \mathrm{D}$

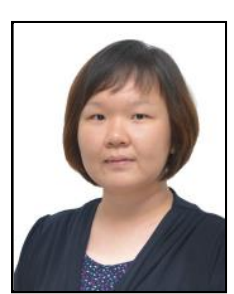

Fang-Fang Chua is a senior lecturer of the Faculty of Computing and Informatics, Multimedia University. She obtained the bachelor of information technology (hons) software engineering from Multimedia University, Malaysia. She then received her master of information technology from The University of Melbourne, Australia and Ph.D. (information technology) from Multimedia University, Malaysia. Her research includes service-oriented computing, collaborative learning, adaptive coaching, mobile computing and social networking. She has published several research papers and has also been invited as a reviewer and program committee in various reputed international journals and conferences. She is involved in multiple research projects funded by JICA \& SASTREPS, TM R\&D, FRGS and PRGS. She is currently conducting a funded research project in learning analytics.

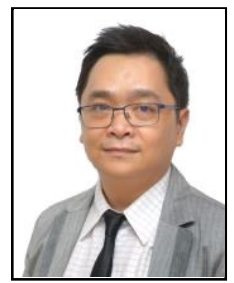

Tek-Yong Lim is a senior lecturer of Faculty of Computing and Informatics, Multimedia University. His research interests include data analytics, prediction interval forecasting and stochastic process. 